\title{
Broadband Circular Polarization Antenna Based on Inverted Suspended Circular Patch with Square Slot
}

\author{
Hamizan Abu Bakar, Mohamad Zoinol Abidin Bin Abd Aziz, Badrul Hisham Ahmad, Nornikman Hassan \\ Centre for Telecommunication Research and Innovation (CeTRI), Faculty of Electronics and Computer Engineering \\ Universiti Teknikal Malaysia Melaka (UTeM), 76100 Durian Tunggal, Melaka, Malaysia
}

\begin{abstract}
In this paper, an inverted suspended circular patch with square slot design is proposed for broadband circular polarized antenna. The antenna was designed based on L-probe technique and air gap of $10 \mathrm{~mm}$ distance between substrate and copper ground. L-probe technique is used in this antenna design to feed the $50 \mathrm{Ohm}$ SMA connector signal through the feedline to the antenna structure. The proposed antenna had been designed and simulated by using computer simulation technology (CST) software. This antenna design is targeted for wireless local area network (WLAN) application which operating frequency at 2.4 GHz. Antenna performances in term of return loss, resonant frequency, bandwidth, gain, axial ratio, directivity, total efficiency and radiation pattern at the design frequency are analyzed. Result of simulation show that the proposed antenna achieved axial ratio below $3 \mathrm{~dB}$ which is $0.62 \mathrm{~dB}$ with return loss $-35.60 \mathrm{~dB}$ at targeted frequency. Comparison result of simulation and measurement show that the return loss bandwidth (RLBW) and realized gain of the antenna at $2.4 \mathrm{GHz}$ frequency decreases from $556 \mathrm{MHz}$ to 354 $\mathrm{MHz}$ with gain $7.76 \mathrm{~dB}$ to $4.54 \mathrm{~dB}$. However, the proposed antenna covers a wider bandwidth of $2.4 \mathrm{GHz}$ where both simulation and measurement bandwidth is over $350 \mathrm{MHz}$.
\end{abstract}

\section{Introduction}

Microstrip patch antennas have been widely used due to their advantages of low profile, ease of fabrication, inexpensive, light weight and ease of integration with active Radio Frequency (RF) devices [1]. The basic and most commonly shape used to design microstrip antenna is the rectangular patch antenna. As in [2], the antenna is construct based on a rectangular patch design with two cutting slots to get an E-shaped antenna design which yields circular polarization. Instead of rectangular is the basic and most commonly used shape, microstrip patch antenna could be in lot of various shapes such as circular, square, elliptical and triangular [3].

However, microstrip patch antenna is restricted with narrow bandwidth and poor gain. As a way to solve this issue, several modifications need to be done are included adding slot [4,5], fed by L-probe [6-10] and others. The major advantage of L-probe fed is the ability of the design to improve bandwidth no less than $5 \%$ from its centre frequency [7] while keeping reasonable radiation properties. In [7], the simulated impedance bandwidth is $11.04 \%$ covering from $2.444 \mathrm{GHz}$ to $2.729 \mathrm{GHz}$ is obtained at $-10 \mathrm{~dB}$ return loss.

The polarization of microstrip patch antenna may be categorized into linear polarization (LP) and circular polarization $(\mathrm{CP})$. In a circular polarized antenna, the plane of polarization rotates in a circle forming one complete turn during one period of the wave. A circular polarized wave radiates signal in both the horizontal and vertical planes and all planes in between. Circular polarization is regarded as the well-known polarization schemes mainly because it can offer better mobility and weather penetration than linear polarization [11,12]. Other than that, CP also has the advantages of the reduction of "Faraday rotation", mitigation of multipath fading and immunity of polarization mismatching between transmitting and receiving antennas [13]. Microstrip patch antenna in their basic form normally provides linear polarization, but by certain modification it can provide circular polarization. The circular polarized antenna can be obtained by using single or double feed [1,14], truncated corner [2,15], slot [15], double layer.

In this work, a wideband L-probe inverted suspended circular patch with square slot antenna is presented. The wideband was obtained by the separation of air gap between the substrate and copper ground plane. The proposed circular patch antenna was designed for circular polarization at $2.4 \mathrm{GHz}$ frequency.

\section{Antenna Design}

In this study, the antenna was designed using an FR4 board with dielectric constant, $\varepsilon_{\mathrm{r}}$ of the substrate $=4.4$, tangent loss, $\tan \delta=0.019$, substrate thickness, $\mathrm{h}=1.6$ $\mathrm{mm}$ and copper thickness, $\mathrm{t}=0.035 \mathrm{~mm}$. To represent as L-probe feed, the antenna was feed with the SMA coaxial probe connector from ground layer through the feedline of the antenna structure. The width $\left(\mathrm{W}_{\mathrm{f}}\right)$ and length $\left(\mathrm{L}_{\mathrm{f}}\right)$

\footnotetext{
* Corresponding author: mohamadzoinol@utem.edu.my
} 
of feedline is 3.1 and $13 \mathrm{~mm}$ respectively. The feedline and the circular patch with square slot antenna were designed at the bottom substrate of the antenna which is thus defined as inverted suspended. Where at the upper substrate is just a plain substrate without any patch layer. The antenna design and its ground plane were separated by an air gap with $10 \mathrm{~mm}$ distance.

\subsection{Configuration of inverted suspended circular patch antenna with square slot design}

Configuration of the inverted suspended circular patch antenna design is demonstrated as in Fig. 1. As shown in Fig. 1 (a) and (b) is the front view (plain substrate) and back view (with feedline and circle patch) of the antenna respectively. While, in Fig. 1 (c) and (d) shows the enlargement view and vertical view of the antenna where the square slot position can clearly be seen in Fig. 1 (c) before being subtract with the circular patch design.

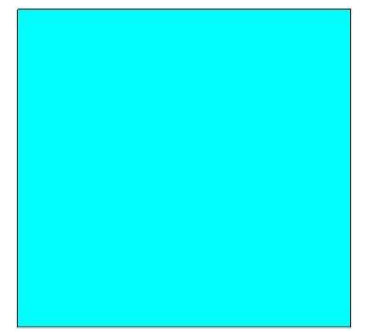

(a)

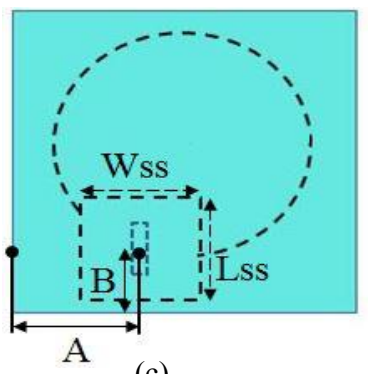

(c)

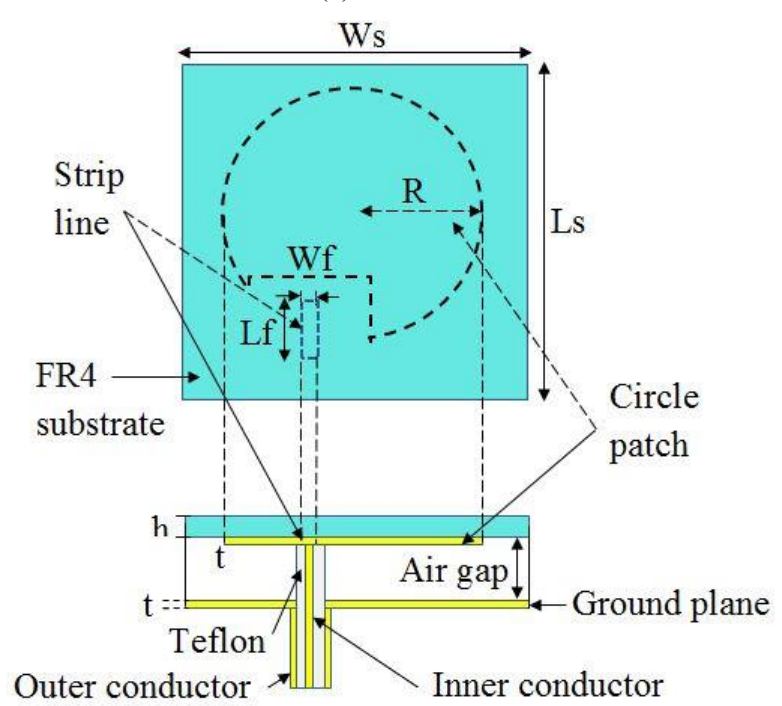

(d)

Fig. 1. Configuration of L-probe inverted suspended circular patch with square slot antenna (a) front view (b) back view (c) enlargement view and (d) vertical view.

\subsection{Prototype view of fabricated inverted suspended circular patch antenna with square slot design}

As demonstrated in Fig. 2 (a) and (b) is the fabricated prototype front view and side view of the antenna. As shown in Fig. 2 (a), the antenna width and length of substrate and copper ground layer is the same which is $80 \times 80 \mathrm{~mm}$.

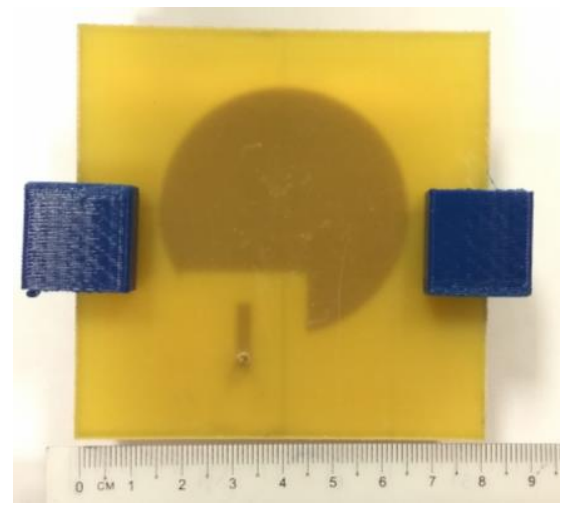

(a)

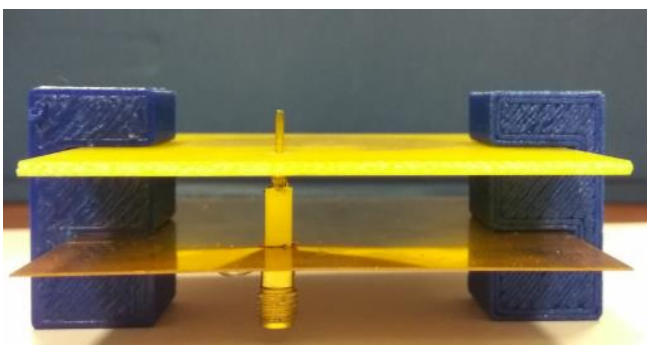

(b)

Fig. 2. Fabricated prototype of L-probe inverted suspended circular patch with square slot antenna (a) front view and (b) side view.

The length and width of the substrate are indicated as $L_{s}$ and $W_{s}$, whereas $L_{s s}$ and $W_{s s}$ are used for the square slot. The size of square slot was decided according to the best result performance of parametric study. The ideal dimension for the antenna is tabulated as in Table 1.

Table 1. Dimension of L-probe inverted suspended circular patch with square slot antenna design.

\begin{tabular}{|c|c|c|}
\hline $\begin{array}{c}\text { Design } \\
\text { Parameter }\end{array}$ & $\begin{array}{c}\text { Dimension } \\
(\mathbf{m m})\end{array}$ & Description \\
\hline Air gap & 10 & Air gap \\
\hline $\boldsymbol{h}$ & 1.6 & Thickness of substrate \\
\hline $\boldsymbol{t}$ & 0.035 & Thickness of copper \\
\hline $\boldsymbol{A}$ & 32 & Middle of feed to substrate \\
\hline $\boldsymbol{B}$ & 20 & Middle of feed to substrate \\
\hline $\boldsymbol{R}$ & 25 & Radius of circle patch \\
\hline $\boldsymbol{L}_{\boldsymbol{f}}$ & 13 & Length of feed \\
\hline $\boldsymbol{L}_{\boldsymbol{s}}$ & 25 & Length of square slot \\
\hline $\boldsymbol{L}_{\boldsymbol{s}}$ & 80 & Length substrate \\
\hline $\boldsymbol{W}_{\boldsymbol{f}}$ & 3.1 & Width of feed \\
\hline $\boldsymbol{W}_{\boldsymbol{s s}}$ & 25 & Width of square slot \\
\hline $\boldsymbol{W}_{\boldsymbol{s}}$ & 80 & Width of substrate \\
\hline
\end{tabular}




\section{Result and discussion}

This section discusses the antenna parameters which include the return loss (RL), resonant frequency $\left(f_{r}\right)$, return loss bandwidth (RLBW), axial ratio (AR), directivity, realized gain, total efficiency, axial ratio bandwidth (ARBW) and radiation pattern of the antenna. The antenna performance at $2.4 \mathrm{GHz}$ frequency were analysed and investigated. Comparison of simulation and measurement result of return loss bandwidth, resonant frequency and realized gain at $2.4 \mathrm{GHz}$ frequency is demonstrated and tabulated as in Fig. 3 and Table 3.

\subsection{Return loss (RL), resonant frequency $\left(f_{r}\right)$ and bandwidth (BW)}

Return loss of antenna need to be more than $-10 \mathrm{~dB}$ in order to get more than $90 \%$ antenna efficiency. According to the simulation and measurement result as demonstrated in Figure 3, the return loss of the designs at $2.4 \mathrm{GHz}$ frequency achieved below than $-10 \mathrm{~dB}$ which is $-35.6 \mathrm{~dB}$ and $-20.3 \mathrm{~dB}$ with bandwidth (BW) greater than $350 \mathrm{MHz}$. The resonant frequency of the simulation result is at $2.398 \mathrm{GHz}$ with $-35.8 \mathrm{~dB}$ return loss, while the measurement result shifts a little bit to higher frequency which is at $2.42 \mathrm{GHz}$ with return loss dropped slightly to $-21.5 \mathrm{~dB}$.

The simulation bandwidth of the antenna is $556 \mathrm{MHz}$ which ranging from the frequency of $2.20 \mathrm{GHz}$ until $2.76 \mathrm{GHz}$. While the bandwidth of measurement is 354 $\mathrm{MHz}$, it is less compared than the simulation bandwidth. However, both simulation and measurement bandwidth still cover a wider operation bandwidth at $2.4 \mathrm{GHz}$ which is over $350 \mathrm{MHz}$.

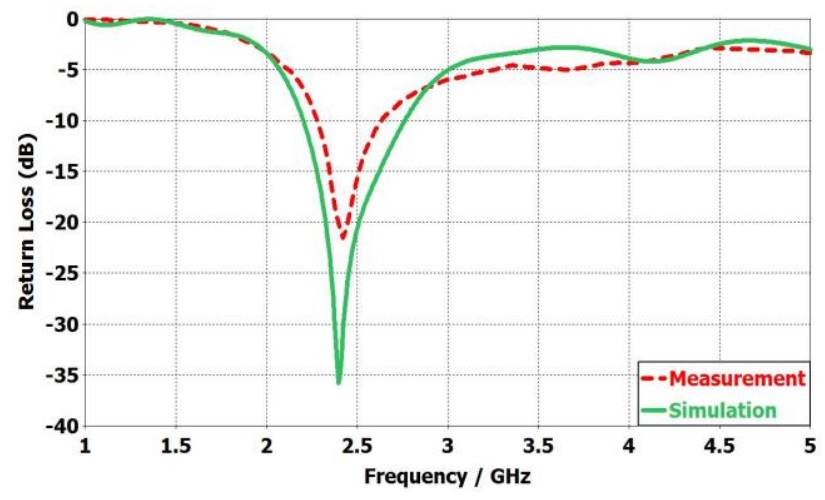

Fig. 3. Comparison of simulated and measured return loss for the inverted suspended circular patch with square slot antenna design.

\subsection{Directivity (Dir.) and total efficiency (Tot. Effc.)}

Fig. 4 illustrates the simulation view for the graph of directivity $(\mathrm{dBi})$ over frequency. Based on the simulation results, the directivity for the antenna design at $2.4 \mathrm{GHz}$ is $7.94 \mathrm{dBi}$. The highest directivity of the antenna is at $2.5 \mathrm{GHz}$ with $8.18 \mathrm{dBi}$ respectively. The directivity above $8 \mathrm{dBi}$ covered from $2.42 \mathrm{GHz}$ until $2.61 \mathrm{GHz}$ frequency range.
Based on Fig. 5, the highest total efficiency of the antenna is at $2.4 \mathrm{GHz}$ which is $-0.18 \mathrm{~dB}$. Total efficiency must be more than $-3 \mathrm{~dB}$ to get more than $50 \%$ antenna efficiency at $2.4 \mathrm{GHz}$ frequency. Total efficiency of the antenna also can be calculated based on result of gain minus directivity.

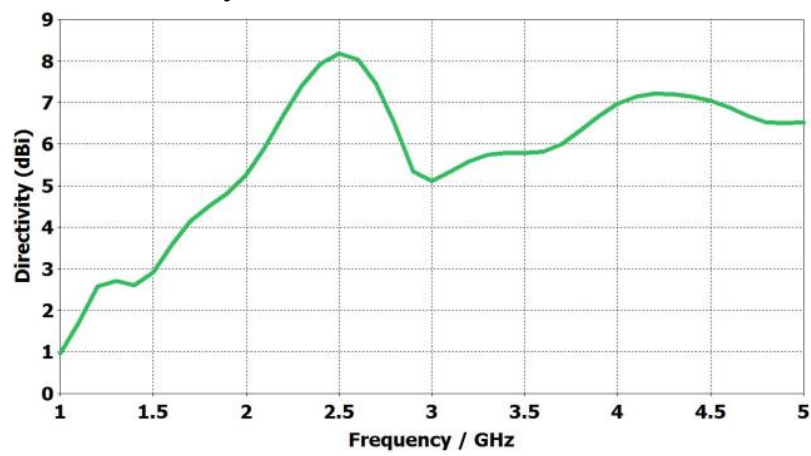

Fig. 4. Simulated directivity for inverted suspended circular patch with square slot antenna design.

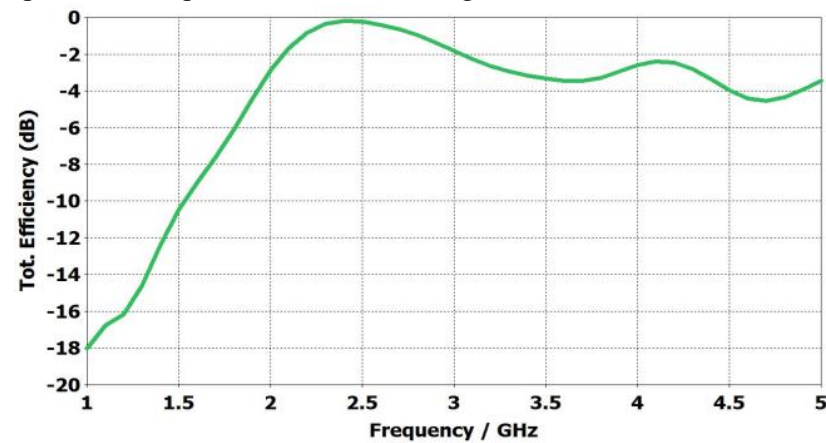

Fig. 5. Simulated total efficiency for inverted suspended circular patch with square slot antenna design.

\subsection{Axial ratio (AR)}

In Fig. 6, the polarization for the antenna may be identified according to the axial ratio analysed by the CST software. The axial ratio of circular polarized (CP) should be below than $3 \mathrm{~dB}$. Based on Fig. 6, the minimum axial ratio is at $2.1 \mathrm{GHz}$ frequency which is $0.07 \mathrm{~dB}$. While at $2.4 \mathrm{GHz}$, the axial ratio for the antenna design is $0.62 \mathrm{~dB}$. The axial ratio bandwidth (ARBW) below than $3 \mathrm{~dB}$ is $1120 \mathrm{MHz}$ which is covered from frequency range of $1.37-2.49 \mathrm{GHz}$. It was indicated that for this inverted suspended circular patch with square slot antenna design, it can operate and presented a good circular polarization at $2.4 \mathrm{GHz}$.

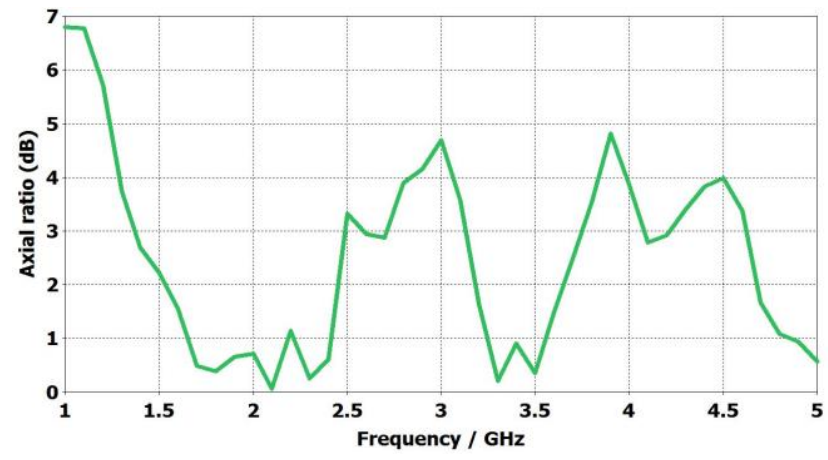

Fig. 6. Simulated axial ratio for inverted suspended circular patch with square slot antenna design. 


\subsection{Radiation pattern}

Radiation pattern of antenna is measured in far field region. Fig. 7 demonstrate the comparison of simulated and measured radiation pattern of the antenna at $2.4 \mathrm{GHz}$ when phi $=0^{\circ}$, phi $=90^{\circ}$ and theta $=90^{\circ}$. The radiation pattern gained from measurement result is quite similar with the simulation result.

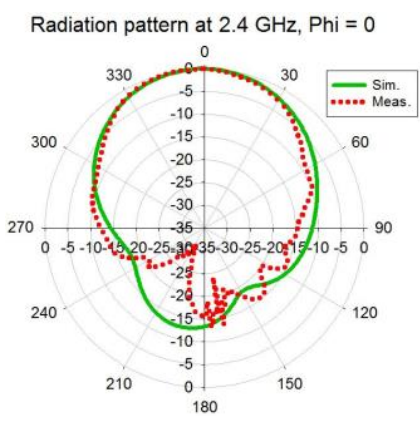

(a)

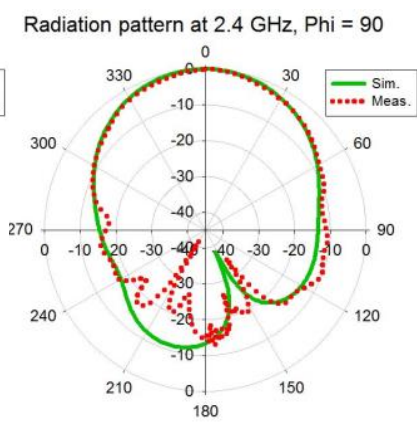

(b)

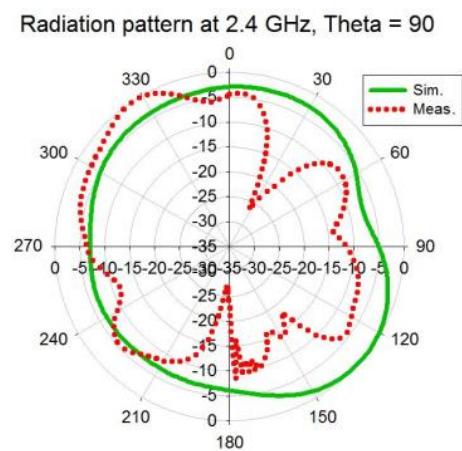

(c)

Fig. 7. Comparison of simulated and measured radiation pattern for inverted suspended circular patch with square slot antenna design at $2.4 \mathrm{GHz}$ frequency (a) $\mathrm{phi}=0^{\circ}$ (b) $\mathrm{phi}=90^{\circ}$ (c) theta $=90^{\circ}$.

Table 2 shows the result of axial ratio bandwidth (ARBW), axial ratio (AR), directivity and total efficiency at $2.4 \mathrm{GHz}$. While, Table 3 shows the result of return loss bandwidth (RLBW), resonant frequency $\left(f_{r}\right)$, return loss and realized gain at $2.4 \mathrm{GHz}$. According to Table 3, the simulation result of gain is $7.76 \mathrm{~dB}$ and based on calculation of gain for the data taken from measurement result, the gain is $5.54 \mathrm{~dB}$ respectively. The comparisons of simulation and measurement results for the gain show that the gain for measurement is reduced around $2.22 \mathrm{~dB}$. This might be due to the reduction of return loss for measurement result at 2.4 $\mathrm{GHz}$ from $-35.6 \mathrm{~dB}$ to $-20.3 \mathrm{~dB}$ which is around -15.3 $\mathrm{dB}$ less compared to the simulation result.
Table 2. Performance result of ARBW, AR, directivity and total efficiency of the inverted suspended circular patch with square slot antenna design.

\begin{tabular}{|c|c|c|c|c|c|}
\hline \multirow{2}{*}{$\begin{array}{l}\text { Ant. } \\
\text { Design }\end{array}$} & \multicolumn{2}{|c|}{$\begin{array}{c}\text { Axial Ratio } \\
\text { Bandwidth (ARBW) }\end{array}$} & \multirow{2}{*}{$\begin{array}{c}2.4 \\
\mathbf{G H z} \\
A R \\
\\
(d B)\end{array}$} & \multirow{2}{*}{$\begin{array}{c}2.4 \\
\text { GHz } \\
\\
\text { Dir. } \\
\text { (dBi) }\end{array}$} & \multirow{2}{*}{$\begin{array}{c}2.4 \\
\text { GHz }\end{array}$} \\
\hline & $\begin{array}{l}\text { Freq. } \\
\text { Range } \\
(\mathrm{GHz})\end{array}$ & $\begin{array}{c}B W \\
(G H z)\end{array}$ & & & \\
\hline Sim. & $1.37-2.49$ & 1.12 & 0.62 & 7.94 & -0.18 \\
\hline
\end{tabular}

Table 3. Comparison of simulation and measurement result of return loss bandwidth (RLBW), $\mathrm{f}_{\mathrm{r}}, \mathrm{RL}$ and realized gain at 2.4 $\mathrm{GHz}$.

\begin{tabular}{|c|c|c|c|c|c|c|}
\hline \multirow{2}{*}{$\begin{array}{c}\text { Ant. } \\
\text { Desi } \\
\text { gn }\end{array}$} & \multicolumn{2}{|c|}{$\begin{array}{c}\text { Return Loss } \\
\text { Bandwidth }\end{array}$} & \multicolumn{2}{|c|}{$\begin{array}{l}\text { Resonant } \\
\text { Freq. }\left(f_{r}\right)\end{array}$} & \multirow{2}{*}{$\begin{array}{c}2.4 \\
\mathrm{GHz} \\
R L \\
(d B)\end{array}$} & \multirow{2}{*}{$\begin{array}{c}2.4 \\
\text { GHz } \\
\text { Gain } \\
\text { (dB) }\end{array}$} \\
\hline & $\begin{array}{l}\text { Freq. } \\
\text { range } \\
(\mathrm{GHz})\end{array}$ & $\begin{array}{c}B W \\
(M H z)\end{array}$ & $\begin{array}{c}\text { Freq } \\
(G H z)\end{array}$ & $\begin{array}{l}R L \\
(d B)\end{array}$ & & \\
\hline Sim. & $\begin{array}{l}2.20- \\
2.76\end{array}$ & 556 & 2.398 & $\begin{array}{c}- \\
35.8\end{array}$ & -35.6 & 7.76 \\
\hline Meas & $\begin{array}{l}2.28- \\
2.63\end{array}$ & 354 & 2.42 & $\begin{array}{c}- \\
21.5\end{array}$ & -20.3 & 4.54 \\
\hline
\end{tabular}

\section{Conclusions}

In this paper, antenna with the operating frequency at 2.4 $\mathrm{GHz}$ which is for WLAN application is proposed. The antenna was designed based on the L-probe technique of inverted suspended circular patch with a square slot and air gap substrate between FR4 substrate and ground plane. Result performance of the proposed antenna such as return loss, resonant frequency, bandwidth, RLBW, axial ratio, ARBW, realized gain, directivity, total efficiency and radiation pattern at $2.4 \mathrm{GHz}$ are analyzed. From the observation on the simulation result at 2.4 $\mathrm{GHz}$, axial ratio of the antenna is circular polarized where it is $0.62 \mathrm{~dB}$ with return loss $-35.60 \mathrm{~dB}$ and total efficiency above $-3 \mathrm{~dB}$ which is $-0.18 \mathrm{~dB}$. The bandwidths of both simulation and measurement result for the antenna is more than $350 \mathrm{MHz}$ thus meet the requirement of the broadband antenna operation. The results of measurement for the gain were reduced compared to the simulation result which is from $7.76 \mathrm{~dB}$ to $4.54 \mathrm{~dB}$. Overall, the simulation and measurement result for the proposed design meet requirement for circular polarized antenna and broadband operation. The utilization of L-probe fed with a thick air-filled substrate leads to bandwidth enhancement. In future, in order to assemble as more compact or smaller sized antenna, size reduction can be achieved by incorporating more slots on the circular patch antenna design or with the integration of metasurface (MS) structure. Antenna with large bandwidth, compact in size and can operate as circular polarization is a major consideration in the practical application for wireless communication system. 


\section{Acknowledgements}

The researchers wanted to be thankful to Universiti Teknikal Malaysia Melaka (UTeM) for helping in acquired the data and material in the development for our tasks. We also would like to thank to the Government of Malaysia which offer MyBrain15 program for financing this tasks under the research grant TRGS/1/2014/FKEKK/02/1/D00001 from Ministry of Higher Education (MOHE). Furthermore, we equally show appreciation to the anonymous referees whose comments resulted into a much better presentation of our tasks.

\section{References}

1. Balanis, C. A., Antenna Theory: Analysis and Design $4^{\text {th }}$ Edition, John Wiley \& Sons, Inc., New York, (2016).

2. D. Prajakta, B. Chandan and S. Tazeen. Design of modified E-shape microstrip patch antenna for circular polarization. International Journal of Emerging Technology and Advanced Engineering, vol. 3, Issue 10, pp. 247-250 (2013).

3. C. Hannachi and S. O. Tatu, Performance Comparison of $60 \mathrm{GHz}$ Printed Patch Antennas with different Geometrical Shapes using Miniature Hybrid Microwave Integrated Circuits Technology. IET Microwaves, Antennas and Propagation, Volume 11, Issue 1, Pages 106-112 (2017).

4. R. K. Pandey and T. Shanmuganantham, Miniaturization and Bandwidth Enhancement of a Wideband Slotted Microstrip Patch antenna. IEEE International Conference on Circuit, Power and computing Technologies (ICCPCT), Article number 7530263, (2016).

5. R. Mishra, R. G. Mishra, P. Kuchhal and R. K. Chaurasia. Optimization of the Dimension of Circular slotted Rectangular Microstrip Antenna for Wide Band wireless applications. Interbational Conference on Recent Advances and Innovations in Engineering (ICRAIE), Article number 7939468, (2016).

6. K. S. Phoo, M. Z. A. Abd. Aziz, B. H. Ahmad, M. A. Othman, M. K. Suaidi and F. Abd. Malek. Investigation of Broadband Inverted Suspended Rectangular Patch Linear Polarized Antenna. 2014 IEEE International Conference on Control System, Computing and Engineering (ICCSCE), IEEE, pp. 236-240 (2014).

7. M.T Ali, N. Nordin, N. Ya'acob and M. N. Md Tan. Design of Wideband Microstrip Patch Antenna Using L-Probe Fed at $2.6 \mathrm{GHz}$. International Conference on Computer and Communication Engineering (ICCCE), pp. 961-965 (2012).

8. L. Wang, Y. X. Guo and W. Sheng, A 60-GHz Wideband L-probe Patch Antenna Array with Gain Enhanced Structure based on LTCC Technology. Asia-Pacific Microwave Conference Proceedings (APMC), Pages 151-153 (2012).

9. J. Jia, C. Lu, Z. Li and Y. Jie, Design of Broadband Circularly Polarized High Gain Microstrip Antenna with L-shaped Probe Feed. International Conference on Microwave and Milimeter Wave Technology (ICMMT), Volume 3, Pages 1007-1010 (2012).

10. M. T. Ali, N. Nordin, I. Pasya and M. N. M. Tan, HShaped Microstrip Patch Antenna using L-probe Fed for Wideband Applications. Proceedings of $6^{\text {th }}$ European Conference on Antennas and Propagation (EuCAP), Article number 6206166, Pages 28272831 (2012)
11. Cai, Y.M., Li, K., Yin, Y. Z. and Hu, W. Broadband Circularly Polarized Printed Antenna with Branched Microstrip Feed. IEEE Antennas and Wireless Propagation Letters, Vol. 13. 674-677 (2014).

12. Wu, J. J., Ren, X. S., Li, Z. X. and Yin, Y. Z., Modified'Square Slot Antennas for Broadband Circular Polarization. Progress In Electromagnetics Research C, Vol. 38, 1-14 (2013).

13. S. Gao, Q. Luo, and F. Zhu, circularly Polarized Antennas. Hoboken, NJ, USA: Wiley (2013).

14. Xu, Y.X., Gong, S.X. and Guan, Y. Design of a Double Feed circularly Polarized Rectangular Microstrip Patch Antenna on a Circular Asymmetrical Carrier. International Conference on Microwave and Milimeter Wave Technology (ICMMT), Volume 3, Pages 965-968 (2012).

15. Deshmukh, A. A., Singh, D. and Verma, P., Analysis and Design of Circular Slot Cut Corner Truncated Rectangular Microstrip Antenna. $2^{\text {nd }}$ International Conference on Advances in Electrical, Electronics, Information, Communication and BioInformatics, IEEE - AEEIC, Pages 627-631 (2016). 